\title{
ON THE HYDROSTATIC STOKES APPROXIMATION WITH NON HOMOGENEOUS DIRICHLET BOUNDARY CONDITIONS
}

\author{
C. Amrouche, F. Dahoumane, R. Luce and G. Vallet
}

Abstract. We deal with the hydrostatic Stokes approximation with non homogeneous Dirichlet boundary conditions. After having investigated the homogeneous case, we build a lifting operator of boundary values related to the divergence operator, and solve the non homogeneous problem in a cylindrical type domain.

Mathematics subject classification (2010): 34C35, 35B40, 35Q30, 76D05.

Keywords and phrases: hydrostatic approximation, De Rham's lemma, lifting operator, primitive equations, non homogeneous Dirichlet conditions.

\section{REFERENCES}

[1] P. AZÉRAD, Analyse des équations de Navier-Stokes en bassin peu profond et de l'équation de transport, Université de Neuchatel, 1996.

[2] P. AZÉRAd AND F. GuilléN-GonZÁlez, Mathematical justification of the hydrostatic approximation in the primitive equations of geophysical fluid dynamics, SIAM J. Maths Anal., 33, 4 (2001), $847-859$.

[3] O. Besson AND M. R. LAYDI, Some estimates for the anisotropic Navier-Stokes and for the hydrostatic approximation, RAIRO, Modélisation Math. Anal. Numér., 26, 7 (1992), 855-865.

[4] O. Besson, M. R. LAYDi AND R. TOUZANI, Un modèle asymptotique en océanographie, C. R. Acad. Sci. Paris, 310, 1 (1990), 661-665.

[5] T. Chacón Rebollo, E. Chacón Vera and R. Lewandowski, Analysis of the hydrostatic approximation in oceanography with convection term, M2AN, Math. Model. Numer. Anal., 34, 3 (2000), 525-537.

[6] V. Girault And P. A. Raviart, Finite element methods for the Navier-Stokes equations, Springer Series in Computational Mathematics, Springer Verlag, 5, 1986.

[7] F. Guillén-GonZÁlez, N. Masmoudi And M. A. Rodriguez-Bellido, Anisotropic estimates and strong solutions of the primitive equations, Differential Integral Equations, 14, 11 (2001), 13811408.

[8] F. Guillén-GonZÁlez And M. A. RodrigueZ-Bellido, On the strong solutions of the primitive equations problem in $2 D$ domains, Nonlinear Anal., 50, 5 (2002), 621-646.

[9] F. Guillén-González, M. A. Rodriguez-Bellido and M. A. Rojas-Medar, Hydrostatic Stokes equations with non-smooth Neumann data, Ann. Inst. H. Poincaré Anal. Non Linéaire, 21, 6 (2004), 807-826.

[10] R. Lewandows Ki, Analyse mathématique et océanographie, Masson, 1997.

[11] J.-L. Lions, R. TEMAM AND S. WANG, On the equations of the large scale Ocean, Nonlinearity, 5 (1992), 237-288.

[12] J.-L. Lions, R. Temam And S. WANG, New formulation of the primitive equations of the atmosphere and applications, Nonlinearity, 5 (1992), 1007-1053.

[13] F. ORTEGón GAllego, On distributions independant of $x_{N}$ in certain non-cylindrical domains and a De Rham lemma with a non-local constraint, Nonlinear Anal., 59, 3 (2004), 335-345.

[14] R. Temam, Sur la stabilité et la convergence de la méthode des pas fractionnaires, Ann. Math. Pura ed Applicata, LXXIX (1968), 191-379. 
[15] R. TEmam AND M. ZIANE, Some mathematical problems in geophysical fluid dynamics, Handbook of Mathematical Fluid Dynamics, 3, 2004.

[16] M. ZIANE, Regularity results for the Stokes type systems, Applicable Analysis, 58 (1995), 263-292. 